\title{
The Arabidopsis ATAF1, a NAC Transcription Factor, Is a Negative Regulator of Defense Responses Against Necrotrophic Fungal and Bacterial Pathogens
}

\author{
Xiao'e Wang, ${ }^{1}$ B. M. Vindhya S. Basnayake, ${ }^{1}$ Huijuan Zhang, ${ }^{1}$ Guojun Li, ${ }^{1}$ Wei Li, ${ }^{1}$ Nasar Virk, ${ }^{1}$ \\ Tesfaye Mengiste, ${ }^{2}$ and Fengming Song ${ }^{1}$ \\ ${ }^{1}$ State Key Laboratory for Rice Biology, Institute of Biotechnology, Zhejiang University-Huajiachi Campus, Hangzhou, \\ Zhejiang 310029, People's Republic of China; ${ }^{2}$ Department of Botany and Plant Pathology, Purdue University, \\ West Lafayette, IN 47907, U.S.A.
}

Submitted 11 February 2009. Accepted 10 June 2009.

\begin{abstract}
Transcription factors of the NAC family are known to be involved in various growth or developmental processes and in regulation of response to environmental stresses. In the present study, we report that Arabidopsis ATAF1 is a negative regulator of defense responses against both necrotrophic fungal and bacterial pathogens. Expression of ATAF1 was downregulated after infection with Botrytis cinerea or Pseudomonas syringae pv. tomato or after treatment with salicylic acid (SA), jasmonic acid, and 1-amino cyclopropane-1-carboxylic acid (the precursor of ethylene biosynthesis). Transgenic plants that overexpress the ATAF1 gene (ATAF1-OE) showed increased susceptibility while expression of an ATAF1 chimeric repressor construct (ATAF1SRDX) exhibited enhanced resistance to $P$. syringae pv. tomato DC3000, B. cinerea, and Alternaria brassicicola. The ataf1 mutant plants showed no significant resistance against the pathogens tested. After inoculation with $B$. cinerea or $P$. syringae pv. tomato DC3000, expressions of defenserelated genes $P R-1, P R-5$. and $P D F 1.2$ were upregulated in the ATAF1-SRDX plants but attenuated or unchanged in the ATAF1-OE plants. In ATAF1-OE plants, SA-induced expression of pathogenesis-related genes and disease resistance against $P$. syringae pv. tomato $\mathrm{DC} 3000$ was partially suppressed. Increased levels of reactive oxygen species (i.e., $\mathrm{H}_{2} \mathrm{O}_{2}$ and superoxide anion) accumulated only in the ATAF1-OE but not in the ATAF1-SRDX plants after Botrytis spp. infection. Our studies provide direct genetic evidence for the role of ATAF1 as a negative regulator of defense response against different type of pathogens.
\end{abstract}

During coevolution with potential microbial pathogens, plants have developed a complex and precisely regulated network of genes to defend themselves against potential invading pathogens. A battery of defense mechanisms and defense genes are coordinately expressed in response to infection. Extensive biochemical, genetic, and genomic studies in Arabidopsis have revealed that salicylic acid (SA)- and jasmonic acid/ethylene (JA/ET)-dependent signaling pathways mediate the expression of defense genes and disease resistance responses (Glazebrook 2005). Generally, the speed and intensity of activation of defense gene expression upon pathogen recognition is critical to establish effective defense responses. In recent years, increas-

Corresponding author: Fengming Song; E-mail: fmsong @zju.edu.cn; Fax: +086-0571-86049815. ing evidence has implicated a range of transcription factors directly or indirectly regulating plant defense responses against pathogens. Transcription factors are grouped into different families on the basis of conserved structural domains that are involved in DNA binding activity. Dozens of transcription factors belonging to the WRKY, ERF, MYB, and bZIP families play important roles in regulation of defense responses (Eulgem and Somssich 2007; Gutterson and Reuber 2004).

NAM, ATAF, and CUC (NAC) transcription factors comprise a large family of proteins, which contain a highly conserved $\mathrm{N}$ terminal DNA-binding domain and a variable C-terminal domain (Olsen et al. 2005). Bioinformatics analyses have identified more than 100 NAC genes existing in the genomes of Arabidopsis and rice. (Ooka et al. 2003; Fang et al. 2008). NAC proteins appear to be unique transcription factors in plants and no homolog has been identified in other eukaryotes thus far (Olsen et al. 2005). Recent studies have implicated NAC proteins as important components in different aspects of plant development, including formation of boundary cells of the meristem, cell division and expansion, lateral root development, senescence, secondary cell wall biosynthesis, and flowering time (Souer et al. 1996; Aida et al. 1997; Sablowski and Meyerowitz 1998; Xie et al. 2000; Guo and Gan 2006; Kim et al. 2006; Zhong et al. 2006; Mitsuda et al. 2005, 2007; Yoo et al. 2007). On the other hand, several NAC proteins from Arabidopsis and rice are believed to be important in the control of responses to abiotic stresses. At least four Arabidopsis dehydration-inducible NAC genes-ANAC019, ANAC055, ANAC072 (RD26), and ATAF1 - and three rice drought stress-inducible NAC genesSNAC1, SNAC2, and OsNAC6 - are associated with drought tolerance, and overexpression of some of these genes in plants confers enhanced drought tolerance (Tran et al. 2004, 2007; Fujita et al. 2004; Hu et al. 2006, 2008; Lu et al. 2007; Nakashima et al. 2008; Zheng et al. 2009). Arabidopsis AtNAC2/ANAC092 and NTL8/NTL9 are involved in salt and osmotic stress responses (He et al. 2005; Kim et al. 2008; Yoon et al. 2008). Moreover, NAC proteins are also involved in iron homeostasis in plants (Uauy et al. 2006; Ogo et al. 2008).

Accumulating evidence indicates that the NAC family proteins play important roles in regulation of plant defense response against pathogens. The first line of evidence came from the potato gene StNAC, which was induced by pathogen attack (Collinge and Boller 2001). It was found that some NAC genes from rapeseed, rice, barley, pepper, and Arabidopsis are induced by pathogen infection or treatment with defense signal molecules (Hegedus et al. 2003; Delessert et al. 2005; Oh et al. 
2005; Ohnishi et al. 2005; Jensen et al. 2007). Functional analyses using T-DNA insertion lines and overexpression in transgenic plants revealed that Arabidopsis ATAF2 and ANAC019/ ANAC055 genes are negative regulators of defense response against the vascular wilt pathogen, Fusarium oxysporum, and the necrotrophic pathogen, Botrytis cinerea, through suppression of defense gene expression (Delessert et al. 2005; Bu et al. 2008). It was also found that Arabidopsis ATAF1 and its barley homologue HvNAC6 contribute to penetration resistance in Arabidopsis against the nonhost pathogen, Blumeria graminis f. sp. hordei, and in barley against virulent B. graminis f. sp. hordei (Jensen et al. 2007, 2008). Furthermore, some NAC proteins are also involved in plant-virus interactions by interacting with viral components, and disruption of such NAC proteins in rice confers enhanced disease resistance against Rice dwarf virus (Ren et al. 2000; Selth et al. 2005; Jeong et al. 2008; Yoshii et al. 2008). Thus, the NAC proteins have diverse functions in plant disease resistance.

Recently, it was found that ATAF1, one of the first identified NAC transcription factors in Arabidopsis, negatively regulates drought tolerance but plays an important role in penetration resistance against the nonhost pathogen $B$. graminis $\mathrm{f}$. sp. hordei in Arabidopsis (Jensen et al. 2007, 2008; Lu et al. 2007). In the present study, we studied the function of Arabidopsis

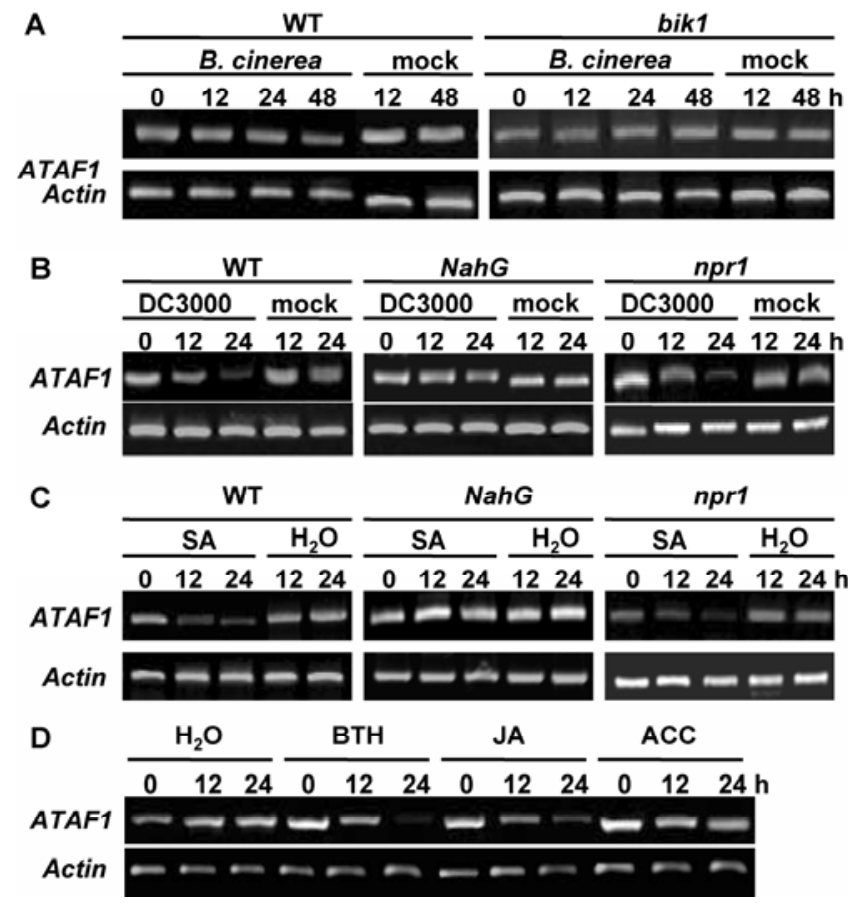

Fig. 1. Expression of ATAF1 gene is downregulated in Arabidopsis plants in response to pathogen infection and chemical treatments. $\mathbf{A}$ and $\mathbf{B}$, Expression of ATAF1 in wild-type (WT) and mutant plants in responses to $\mathbf{A}$, Botrytis cinerea and B, Pseudomonas syringae pv. tomato DC3000 infection. Four-week-old WT (Col-0) and mutant (bikl, NahG, and nprl) plants were inoculated by spraying with spores of $B$. cinerea $\left(2 \times 10^{5}\right.$ spores $\left./ \mathrm{ml}\right)$, by infiltration with $P$. syringae pv. tomato DC3000 (optical density at 600 $\mathrm{nm}=0.002$ ), and by treatment with corresponding solutions. The inoculated leaves were collected at indicated times after inoculation for RNA isolation. Expression of $A T A F 1$ was analyzed using reverse-transcriptase polymerase chain reaction (RT-PCR) (32 cycles for ATAF1 and 26 cycles for actin gene) with gene-specific primers. $\mathbf{C}$ and $\mathbf{D}$, Expression of ATAF1 in WT and mutant plant responses to treatments with chemical inducers. Four-week-old WT (Col-0) and mutant (NahG and nprl) plants were treated by foliar spraying with $1 \mathrm{mM}$ salicylic acid (SA), $0.3 \mathrm{mM}$ benzothiadiazole (BTH), $100 \mu \mathrm{M}$ jasmonic acid (JA), $100 \mu \mathrm{M}$ ACC, or water as controls. Sample collection and RT-PCR analysis of ATAF1 expression were performed as in A and B. Samples for 0-h controls were collected immediately after inoculation or treatment.
ATAF1 in regulation of defense responses. The disease phenotype of T-DNA insertion mutant, overexpression, and chimeric repressor transgenic plants were analyzed. Expression of ATAF1 was downregulated after infection with Botrytis cinerea or Pseudomonas syringae pv. tomato DC3000 or after treatment with SA and JA. Transgenic plants with overexpression of the $A T A F 1$ gene (ATAF1-OE) showed increased susceptibility while transgenic plants expressing an $A T A F 1$ chimeric repressor construct (ATAF1-SRDX) exhibited enhanced resistance against $P$. syringae pv. tomato DC3000, B. cinerea, and Alternaria brassicicola. After infections by $B$. cinerea or $P$. syringae pv. tomato DC3000, expression of defense genes was upregulated in the ATAF1-SRDX plants but downregulated in the ATAF1-OE plants. SA-induced expression of pathogenesisrelated $(P R)$ genes and disease resistance against $P$. syringae pv. tomato DC3000 was partially suppressed in ATAF-OE plants. Reactive oxygen species (ROS) accumulated only in the ATAF1-OE but not in the ATAF1-SRDX plants after Botrytis spp. infection. Our studies provide direct genetic evidence for the role of ATAF1 as a negative regulator of defense against different type of pathogens.

\section{RESULTS}

Downregulation of $A T A F 1$ expression in response to pathogen infection and inducer treatment.

The ATAF1 gene encodes a 289 -amino-acid protein with a conserved NAC domain at its $\mathrm{N}$ terminus. Phylogenetic tree analysis revealed that ATAF1 has approximately 59.5 to $71.1 \%$ identity with ANAC032 (At1g77450), ATAF2 (ANAC081, At5g08790), and ANAC102 (At5g63790). Only ATAF2 and ATAF1 have been previously reported to be involved in defense against Fusarium wilt disease, penetration resistance against nonhost pathogen Blumeria graminis f. sp. hordei, and drought tolerance (Delessert et al. 2005; Lu et al. 2007; Jensen et al. 2007, 2008), whereas no biological function has been assigned to ANAC032 and ANAC102. This implies that this small subgroup of NAC proteins may function against biotic and abiotic stress responses.

To explore the possible involvement of ATAF1 in disease resistance, we analyzed its expression patterns after infection by different pathogens, including $B$. cinerea and $P$. syringae pv. tomato DC3000, in wild-type (WT) and mutant plants with altered disease responses. Expression level of the ATAF1 gene was reduced in WT plants after inoculation with $B$. cinerea, and this reduction was quite evident at $48 \mathrm{~h}$ after inoculation compared with the expression levels in mock-inoculated plants (Fig. 1A). The membrane-anchored BOTRYTIS-INDUCED KINASE1 gene is required for disease resistance against $B$. cinerea and the bikl mutant shows severe susceptibility to necrotrophic fungal pathogens, including $B$. cinerea (Veronese et al. 2006). However, ATAF1 expression was unchanged in the bikl plants after Botrytis spp. infection and the expression levels were comparable with the levels in mock-inoculated plants during a period of $48 \mathrm{~h}$ after inoculation (Fig. 1A). Similarly, expression levels of the ATAF1 gene were decreased in WT plants $12 \mathrm{~h}$ after inoculation with $P$. syringae pv. tomato DC3000 and the expression was significantly reduced at $24 \mathrm{~h}$ after inoculation compared with those in mock-inoculated plants (Fig. 1B). However, expression of the ATAF1 gene showed distinct kinetics in $N a h G$ and nprl plants after infection of $P$. syringae pv. tomato DC3000. The nahG plants fail to accumulate SA whereas $n p r l$ plants are altered in SA signaling; thus, these plant lines represent critical components of the SA-mediated defense response pathway. Compared with the mock-inoculated plants, the NahG plants showed only slight reduction in the expression level of $A T A F 1$ after inoculation; 
whereas the nprl mutant plants showed a significant reduction in expression of $A T A F 1$, especially at $24 \mathrm{~h}$ after inoculation (Fig. 1B). These results indicate that expression of the ATAF1 gene is downregulated in response to pathogen infection and its downregulation depends on SA accumulation and signaling.

We next analyzed the expression patterns of the ATAF1 gene in response to treatments of defense-inducing chemicals. We first compared the expression kinetics of the ATAFl gene in WT, NahG, and nprl plants after SA treatment. Similar to the expression pattern in WT plants after $P$. syringae pv. tomato DC3000 infection, SA treatment suppressed ATAF1 expression compared with the levels in water-treated control plants. The expression of the ATAF1 gene was decreased significantly at $12 \mathrm{~h}$ after inoculation and a further decrease in expression was observed at $24 \mathrm{~h}$ after inoculation (Fig. 1C). In nprl plants, SA treatment also suppressed ATAF1 expression and the expression pattern of the ATAFl gene was similar to that in WT plants after SA treatment (Fig. 1C). However, less reduction of $A T A F 1$ expression was observed in NahG plants after SA treatment (Fig. 1C). Treatment of WT plants with benzothiadiazole (BTH), an analog of SA, also resulted in a significant reduction of ATAFl expression (Fig. 1D). On the other hand, decreases in ATAF1 expression were also observed in WT plants after treatment with JA and 1-aminocyclopropane-1-carboxylate (ACC), although decreases of ATAF1 expression were much more evident in JA-treated plants than that in ACCtreated ones. Together, these results indicate that expression of the ATAF1 gene is also downregulated in response to molecules that induce the SA and JA/ET signaling pathways.

\section{Identification of ataf1, ATAF1-SRDX, and ATAF1-OE lines.}

To determine the biological role of the ATAF1 gene directly, we identified and characterized a T-DNA knockout mutant for the ATAF1 gene. SALK_057618 contains a T-DNA insertion in the third exon of the ATAFl gene and was designated as ataf 1 2 (Fig. 2A), consistent with the previous reports (Lu et al. 2007; Jensen et al. 2007). Homozygous mutant plants were identified by genotyping with $A T A F 1$-specific primers flanking the insertion sites (Fig. 2B). Reverse-transcriptase polymerase chain reaction (RT-PCR) analysis revealed that no full-length ATAF1 transcripts were detected in ataf1-2 homozygous plants and that $A T A F 1$ was expressed normally in heterozygous and WT plants (Fig. 2C). This result indicated that atafl-2 is a null mutant of the ATAF1 gene. The atafl-2 plants exhibited no detectable alteration in morphology (Fig. 2F). However, when tested for disease resistance against $B$. cinerea and $P$. syringae pv. tomato DC3000, no significant difference was observed in ataf 1-2 plants compared with WT plants (see below).

Chimeric repressor silencing technology was used to overcome functional redundancy of genes that may compensate for the ATAFl gene in the atafl mutant (Hiratsu et al. 2003). To do this, the coding sequence of the ATAF1 gene was artificially fused to a plant-specific transcriptional repression domain (LDLDLELRLGFA), named "SRDX", at its C terminus, and this construct was cloned into a binary vector under the control of the Cauliflower mosaic virus (CaMV) 35S promoter, resulting in an ATAF1-SRDX construct (Fig. 2D). In addition, a CaMV 35S promoter-driven overexpression construct was also made by inserting the ATAFl coding sequence into a plant binary vector to make an ATAF1-OE construct. The ATAF1SRDX and ATAF1-OE constructs were introduced into WT (Col-0) Arabidopsis plants through floral dip transformation and transgenic lines that constitutively express ATAF1-SRDX or ATAF1 itself were obtained. Homozygous T3 lines with a single locus of the transgene were screened from T2 seeds based on a 3:1 (Hgr-resistant/Hgr-sesnsitive) segregation ratio on selective medium. Two lines each for ATAF1-SRDX (ATAF1-SRDX nos. 3 and 10) and ATAF1-OE (ATAF1-OE nos. 1 and 7) were chosen for further studies. RT-PCR analysis using ATAF1-specific primers revealed that the expression levels of the ATAF1 gene were higher in the ATAF1-SRDX and ATAF1-OE plants than those in WT and vector-transformed plants (Fig. 2E), indicating that the transgene is expressed correctly. When RT-PCR was performed using an ATAF1-specific primer and a STDX primer, only expression of the ATAF1SRDX transcript was detected in ATAF1-SRDX plants (Fig. $2 \mathrm{E}$ ). During our studies, no significant morphological or growth or development changes were observed in the ATAF1SRDX and ATAF1-OE transgenic plants (Fig. 2F).

\section{Altered disease phenotypes of ATAF1-OE and ATAF1-SRDX transgenic plants against $B$. cinerea and $A$. brassicicola.}

To explore the possible role of ATAF1 in disease resistance response, we first compared the phenotype of the ATAF1-OE,

A
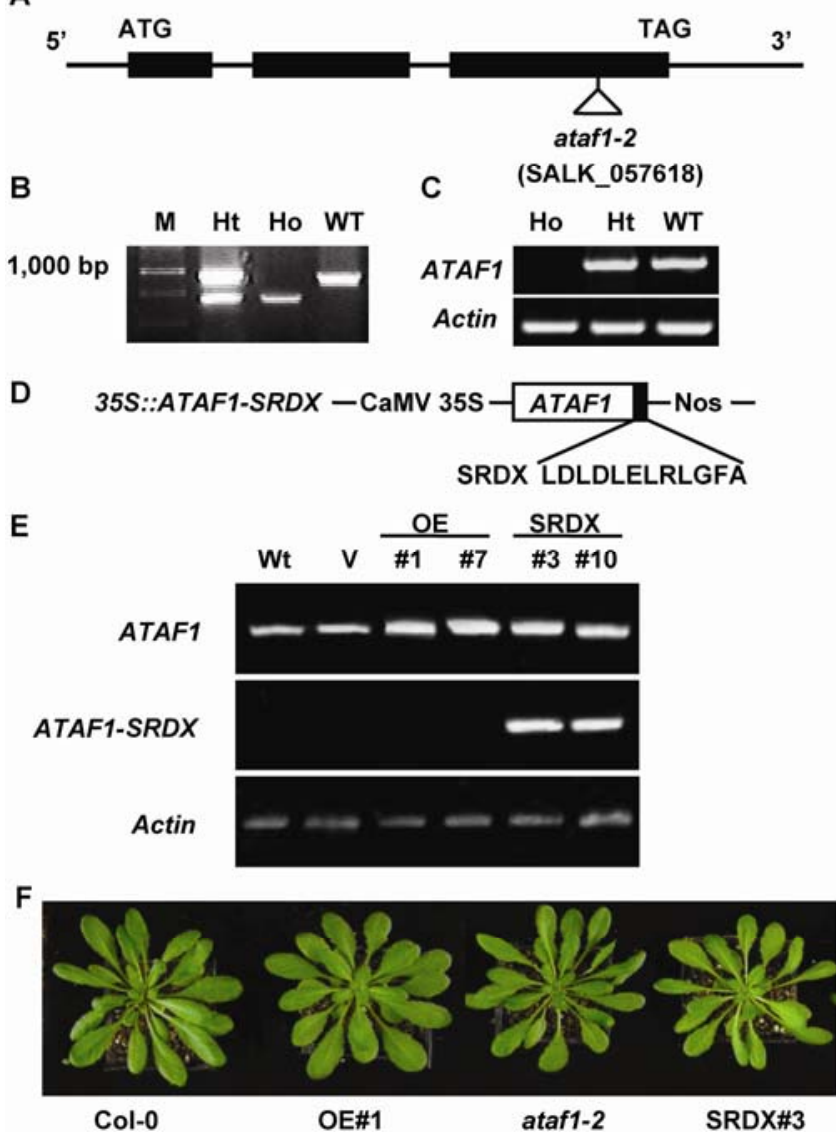

Fig. 2. Characterization of ataf1-2, ATAF1-SRDX, and ATAF1-OE lines. A through $\mathbf{C}$, Characterization of the ataf1-2 T-DNA insertion mutant. A, The T-DNA insertion is located in the third exon of the ATAF1 gene. B, Genotyping for homozygous was performed using gene-specific primers and a $\mathrm{T}$ DNA primer. C, Expression level of the ATAF1 gene in ataf1-2 mutant under normal growth condition was analyzed using reverse-transcriptase polymerase chain reaction (RT-PCR) with gene-specific primers. Ht, heterozygous; Ho, homozygous; WT, wild-type. D through E, Characterization of ATAF1SRDX and ATAF1-OE lines. D, Diagram of the construct used for expression of the chimeric ATAF1 repressor was presented. SRDX, repression domain; CaMV 35S, 35S promoter of Cauliflower mosaic virus; Nos, nopaline synthase terminator. E, Levels of the ATAF1 and ATAF1-SRDX transcripts were analyzed using RT-PCR with a pair of gene-specific primers for ATAF1 transcript and a pair of a gene-specific primer and a SRDX primer for ATAF1-SRDX transcript, respectively. F, Morphology of representative 4week-old WT, ataf1-2 mutant, ATAF1-SRDX, and ATAF1-OE plants. 
ataf1-2, and ATAF1-SRDX plants against two necrotrophic fungal pathogens, $B$. cinerea and $A$. brassicicola. In $B$. cinerea assays, 4-week-old plants were inoculated by spraying a suspension containing $2 \times 10^{5}$ spores $/ \mathrm{ml}$, as described previously (Mengiste et al. 2003; Veronese et al. 2006). In WT plants, typical disease symptoms (i.e., necrotic and chlorotic lesions) were observed 5 days after inoculation (Fig. 3A). However, the necrotic and chlorotic lesions were restricted without leaf damage during the 10-day experimental period and relative chlorophyll contents in leaves of the inoculated plants were reduced by approximately $25 \%$ at 10 days after inoculation (Fig. $3 \mathrm{~A}$ and $\mathrm{B}$ ). Approximately $10 \%$ of the inoculated WT plants were completely decayed due to $B$. cinerea infection at 12 days after inoculation (Fig. 3C). In contrast, the ATAF1-OE

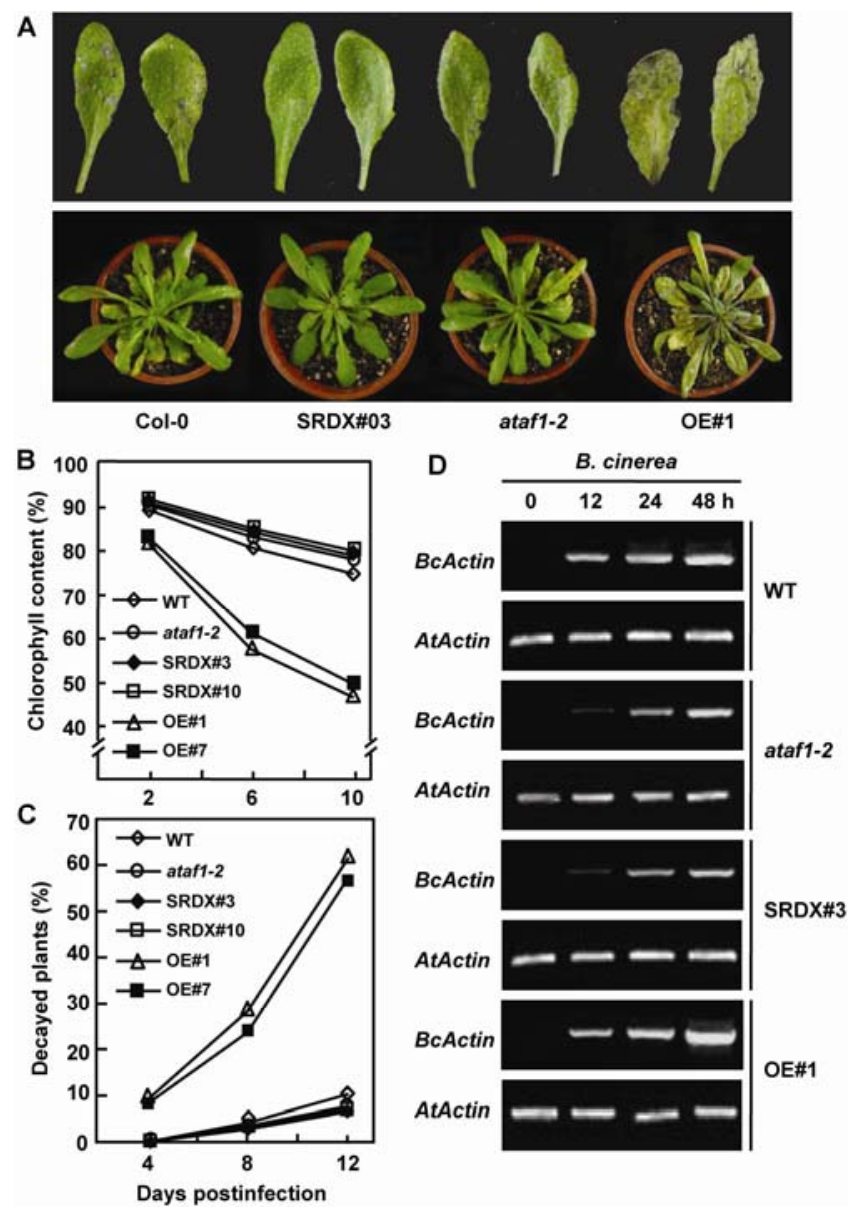

Fig. 3. Altered disease responses of ataf1-2, ATAF1-SRDX, and ATAF1OE plants to Botrytis cinerea. A, Representatives of disease symptom on ataf1-2, ATAF1-SRDX, and ATAF1-OE plants. Four-week-old plants were inoculated by spraying with spores of $B$. cinerea $\left(2 \times 10^{5}\right.$ spores $\left./ \mathrm{ml}\right)$ and photos were taken 5 days after inoculation. $\mathbf{B}$, Changes in chlorophyll content in leaves of wild-type (WT), ataf1-2, ATAF1-SRDX, and ATAF1-OE plants after $B$. cinerea infection. Chlorophyll content in inoculated plants is expressed as percentages of the chlorophyll in the corresponding mockinoculated plants. Chlorophyll was extracted from entire rosette leaves of six mock-inoculated and six B. cinerea-inoculated plants for each line. Data are the means from three independent experiments. C, Percent decay of WT, ataf1-2, ATAF1-SRDX, and ATAF1-OE plants after B. cinerea infection. Plants were scored as decayed when they were completely rotten. Data represented are the means from three different experiments with at least 30 plants per line for each experiment. D, In planta growth of $B$. cinerea in WT, ataf1-2, ATAF1-SRDX, and ATAF1-OE plants. Fungal growth was measured by analyzing expression level of $B$. cinerea actin A (BcActinA) gene using reverse-transcriptase polymerase chain reaction (RT-PCR) with Arabidopsis actin mRNA as a control. RT-PCR was performed using the Botrytis and Arabidopsis actin gene-specific primers, respectively. The experiments were repeated three times, with similar results. plants exhibited severe susceptibility to $B$. cinerea. At 5 days after inoculation, large necrotic and chlorotic lesions that resulted in extensive tissue damage appeared on leaves of the ATAF1-OE no. 3 and 10 plants, resulting in extensive tissue damage (Fig. 3A). The relative chlorophyll contents in leaves of the ATAF1-OE no. 1 and 7 plants were significantly decreased, leading to a reduction of approximately 45 to $50 \%$ (Fig. 3B), and approximately 55 to $65 \%$ of the inoculated plants were completely decayed at 12 days after inoculation (Fig. 3C). However, the ATAF1-SRDX plants showed fewer disease symptoms. No significant necrotic and chlorotic lesions were observed on leaves of the ATAF1-SRDX no. 3 and 10 plants even at 10 days after inoculation (Fig. 3A). The relative chlorophyll content in leaves of the ATAF1-SRDX no. 3 and 10 plants was slightly reduced (approximately 15\%) and only approximately $7 \%$ of the inoculated plants were completely decayed at 12 days after inoculation (Fig. 3B and C). Disease levels in the atafl-2 plants were slightly higher than those in the ATAF1-SRDX plants but were somewhat less than WT plants (Fig. 3A). The relative chlorophyll contents in leaves of the ataf1-2 plants were reduced by approximately $20 \%$ and only approximately $7 \%$ of the inoculated plants were completely decayed at 12 days after inoculation (Fig. 3B and C).

In planta growth of $B$. cinerea in inoculated plants was assessed to further confirm the phenotype observed in the disease assays. The accumulation of the $B$. cinerea actin A (BcActin-A) gene transcript was determined and compared with WT, ATAF1-OE, ATAF1-SRDX, and ataf1-2 plants using RT-PCR. The BcActin-A gene was shown previously to be expressed constitutively in $B$. cinerea during plant infection (Benito et al. 1998); therefore, the amount of its transcript is indicative of the rate of fungal growth in planta. Accumulation of the BcActin-A gene transcript in WT, ATAF1-OE, ATAF1SRDX, and atafl-2 plants were correlated well with the disease symptoms (Fig. 3D). In WT plants, the BcActin-A transcript was detected at $12 \mathrm{~h}$ after inoculation and increased in abundance as infection advanced (Fig. 3D). In the ATAF1-OE plants, the BcActin-A transcript increased faster than in WT plants within $24 \mathrm{~h}$ after inoculation and accumulated to significantly higher levels at 2 days after inoculation (Fig. 3D). However, significantly less of the BcActin- $A$ gene transcript accumulated at $12 \mathrm{~h}$ after inoculation in the atafl-2 and ATAF1SRDX plants. At 2 days after inoculation, the BcActin- $A$ gene transcript in the atafl-2 plants was higher than that in the ATAF1-SRDX plants but was less than WT plants (Fig. 3D). Taken together, these data indicate that overexpression of ATAF1 resulted in increased susceptibility to $B$. cinerea and disruption of ATAF1 led to enhanced resistance to $B$. cinerea, as determined by both the disease phenotype and fungal growth in plant tissue.

We further tested whether altered ATAF1 function affected disease phenotype against another necrotrophic fungal pathogen, A. brassicicola, the causal agent of early blight in cruciferous plants. In these experiments, detached leaves from 4week-old WT, ATAF1-OE, ataf1-2, and ATAF1-SRDX plants were drop inoculated with $5 \mu$ l of spore suspension $\left(5 \times 10^{5}\right.$ spores/ml). In leaves of WT plants, necrotic lesions spread only slightly beyond the point of inoculation and were surrounded by yellow chlorotic zones (Fig. 4A). The lesion sizes measured approximately $4.5 \mathrm{~mm}$ in diameter at 6 days after inoculation (Fig. 4B) and the fungus produced approximately 5,100 spores per lesion at 5 days after inoculation (Fig. 4C). A significant increase in disease symptoms was observed in leaves of the ATAF1-OE plants. The necrotic lesions, surrounded by extensive chlorotic yellowish zones, spread markedly beyond the inoculation sites and the lesion sizes were approximately 6.2 to $6.7 \mathrm{~mm}$ in diameter in the ATAF1-OE no. 1 
and 7 plants (Fig. 4A and B). The fungus produced approximately 14,100 to 15,200 spores per lesion in the ATAF1-OE no. 1 and 7 plants at 5 days after inoculation, resulting in an increase of approximately 176 to $198 \%$ compared with that in WT plants (Fig. 4C). However, in the ATAF1-SRDX no. 3 and 10 plants, only small necrotic lesions appeared at the inoculation sites and these were not surrounded by chlorotic yellowish zone (Fig. 4A). The sizes of the necrotic lesions measured approximately 2.0 to $2.1 \mathrm{~mm}$ in diameter, resulting in a reduction of approximately 55\%, and the fungus produced approximately 3,100 to 3,700 spores per lesion, resulting in a reduction of approximately 27 to $40 \%$ compared with those in WT plants, respectively (Fig. 4B and C). Necrotic lesions surrounded by slight chlorotic yellowish zones in leaves of the ataf1-2 plants were observed (Fig. 4A). The lesion sizes were approximately $2.9 \mathrm{~mm}$ in diameter and the fungus produced approximately 4,000 spores per lesion, slightly larger or more than those in the ATAF1-SRDX plants but slightly smaller or less than those in WT plants, respectively (Fig. 4B and C). These data confirm that overexpression of ATAF1 results in increased susceptibility to A. brassicicola, and that disruption of ATAF1 led to enhanced resistance to A. brassicicola. The increased susceptibility of the ATAF1-OE plants and enhanced resistance of ATAF1-SRDX and atafl-2 plants to both $B$. cinerea and $A$. brassicicola suggest a broad role for ATAF1 in resistance to necrotrophic fungal pathogens.

\section{Altered disease phenotypes of ATAF1-OE and ATAF1-SRDX transgenic plants against $P$. syringae pv. tomato $\mathrm{DC} 3000$.}

We next studied the possible function of ATAF1 in resistance against a bacterial pathogen by analyzing disease phenotypes of the different ATAF1 lines to $P$. syringae pv. tomato DC3000 inoculation. Four-week-old plants were challenged with a normally virulent strain of $P$. syringae pv. tomato

A

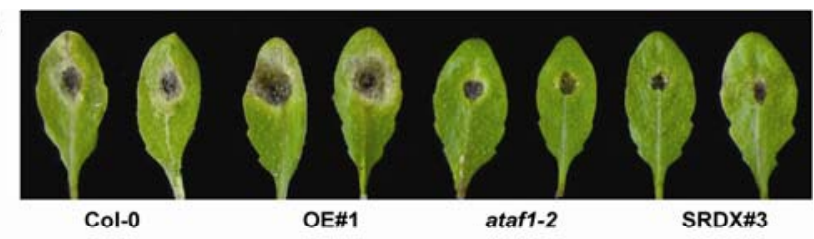

B

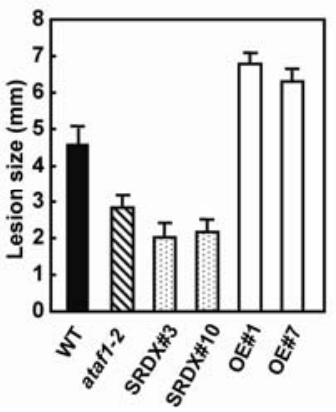

C

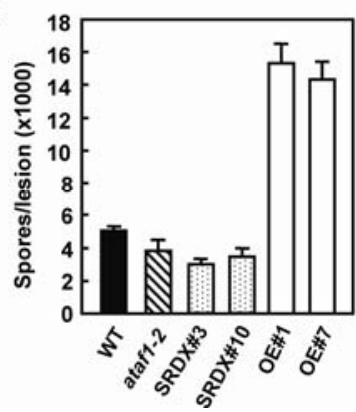

Fig. 4. Altered disease responses of the ataf1-2, ATAF1-SRDX, and ATAF1-OE plants to Alternaria brassicicola. A, Representative disease symptom in ataf1-2, ATAF1-SRDX, and ATAF1-OE plants. Detached leaves from 4-week-old plants were inoculated with a 5- $\mu$ d droplet of $A$. brassicicola spores $\left(1 \times 10^{6}\right.$ spores $\left./ \mathrm{ml}\right)$ and photographed 5 days after inoculation. B, Lesion size on leaves of WT, ataf1-2, ATAF1-SRDX, and ATAF1-OE plants. Lesion size was measured at 5 days after inoculation and data presented are the means \pm standard deviation from at least 40 lesions. C, Sporulation of A. brassicicola on leaves of the WT, ataf1-2, ATAF1-SRDX, and ATAF1-OE plants. Spores were collected from detached inoculated leaves and counted microscopically at 6 days after inoculation. Data represented are the means \pm standard deviation from three independent experiments with at least 20 inoculated leaves taken from each experiment.
DC3000 and disease phenotypes were compared. In WT plants, typical chlorotic lesions were observed and bacterial populations in inoculated leaves were $3.2 \times 10^{6}$ and $1.6 \times 10^{7} \mathrm{CFU} / \mathrm{cm}^{2}$ at 2 and 4 days after inoculation, respectively (Fig. 5A and B). The ATAF1-OE plants developed more severe disease symptoms than WT plants after inoculation with the bacterial pathogen, resulting in extensive chlorotic lesions on the inoculated leaves (Fig. 5A). Similarly, bacterial populations in inoculated leaves of the ATAF1-OE no. 1 and 7 plants were approximately 7.8 to $10.0 \times 10^{7}$ and approximately 6.3 to $12.6 \times 10^{8}$ $\mathrm{CFU} / \mathrm{cm}^{2}$ at 2 and 4 days after inoculation, respectively, resulting in a significant increase (approximately 24- to 79-fold) in bacterial growth relative to WT plants (Fig. 5B). By contrast, only very small chlorotic lesions were observed in inoculated leaves of the ATAF1-SRDX plants, and the bacterial populations in inoculated leaves of the ATAF1-SRDX no. 3 and 10 plants were approximately 6.4 to $8.0 \times 10^{5}$ and approximately 1.6 to $2.5 \times 10^{6} \mathrm{CFU} / \mathrm{cm}^{2}$ at 2 and 4 days after inoculation, respectively, resulting in a significant decrease (approximately four- to sixfold) in bacterial growth compared with WT plants (Fig. 5A and B). Small necrotic lesions appeared in leaves of the atafl-2 plants and the bacterial populations in inoculated leaves of the atafl-2 plants were $1.0 \times 10^{6}$ and $5.0 \times 10^{6} \mathrm{CFU} / \mathrm{cm}^{2}$ at 2 and 4 days after inoculation, respectively (Fig. 5A and B), leading to an approximately threefold decrease in bacterial population compared with WT plants. Disease levels in the atafl-2 plants were higher than those in the ATAF1-SRDX plants but were slightly lower than those in WT plants. These results indicate that constitutive
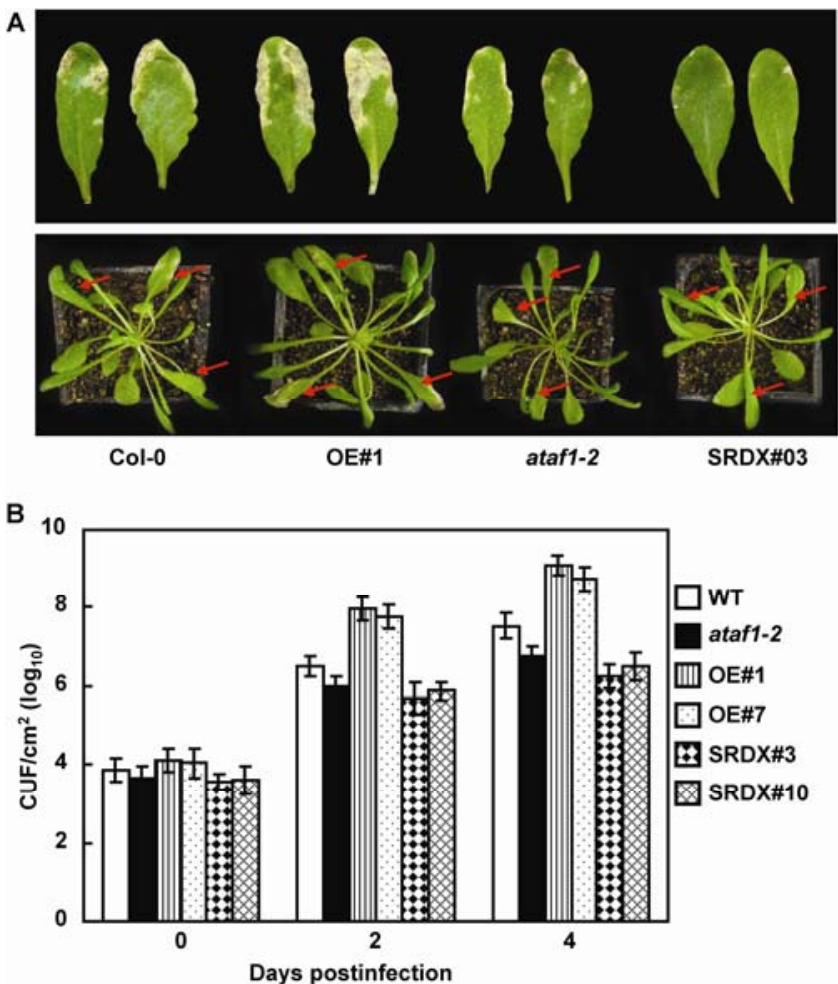

Fig. 5. Altered disease responses in ataf1-2, ATAF1-SRDX, and ATAF1OE plants to Pseudomonas syringae pv. tomato DC3000. A, Representative disease symptom on ataf1-2, ATAF1-SRDX, and ATAF1-OE plants. Four-week-old plants were inoculated by infiltration with $P$. syringae pv. tomato DC3000 (optical density at $600 \mathrm{~nm}=0.002$ ). Photos were taken 4 days after inoculation. B, Bacterial growth in inoculated leaves of WT, ataf1-2, ATAF1-SRDX, and ATAF1-OE plants. Leaf samples were collected at 0,2 , and 4 days after inoculation and bacterial growth in $\mathrm{CFU} / \mathrm{cm}^{2}$ leaf area was measured. Data presented are the means \pm standard deviation from three independent experiments. 
overexpression of ATAF1 resulted in increased growth of the bacteria and enhanced development of disease symptoms and that disruption of ATAF1 led to decreased growth of the bacteria and reduced development of disease symptoms. Therefore, ATAF1 plays a role in resistance against $P$. syringae pv. tomato DC3000 in Arabidopsis.

\section{Different patterns of defense gene expression in the ATAF1-OE and ATAF1-SRDX plants after pathogen infection.}

To determine whether the altered disease responses of different types of pathogens are linked to changes in the regulation of defense genes, we studied the expression of some defense genes (i.e., $P R-1, P R-3, P R-5$, and $P D F 1.2)$ in WT, ATAF1-OE, and ATAF1-SRDX plants grown under normal conditions. No significant difference in expression of the defense genes tested was detected in WT, ATAF1-OE, and ATAF1-SRDX plants grown under normal conditions (data not shown). These results indicate that an altered function of ATAF1 itself did not result in any defense response changes in plants, which is consistent with the notion that both the ATAF1-OE and ATAF1-SRDX plants have no visible morphological and growth or development changes.

We next analyzed and compared the expression levels of defense-related genes in response to $P$. syringae pv. tomato DC3000 infection. In WT plants, the expression levels of the $P R-1, P R-3, P R-5$, and PDF1.2 genes as well as NPRI (a criti-

A

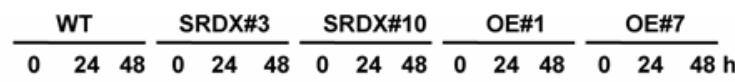

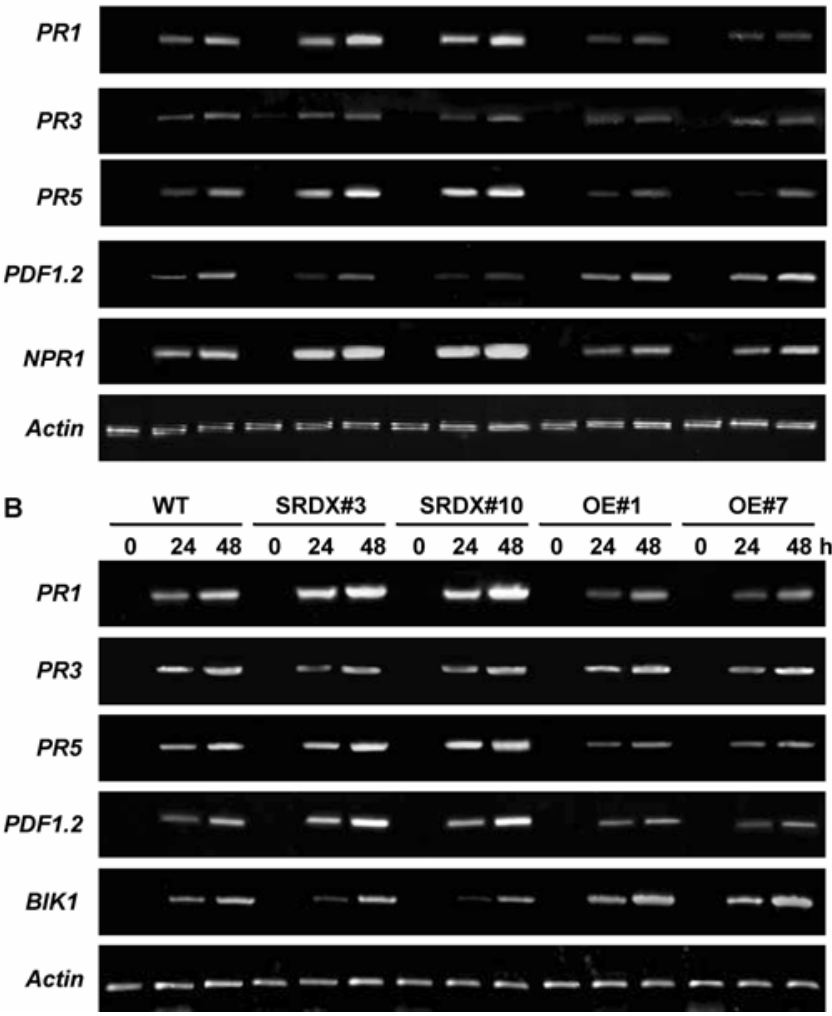

Fig. 6. Expression of defense genes in wild-type (WT), ataf1-2, ATAF1SRDX, and ATAF1-OE plants after inoculation with Botrytis cinerea and Pseudomonas syringae pv. tomato DC3000. Four-week-old plants were inoculated by A, infiltration with $P$. syringae pv. tomato DC3000 (optical density at $600 \mathrm{~nm}=0.002$ ) or $\mathbf{B}$, spraying with spores of $B$. cinerea. Leaf samples were collected at indicated times after inoculation for RNA isolation. Expression of defense genes was analyzed using reverse-transcriptase polymerase chain reaction with gene-specific primers. Actin was used as a control. Two independent experiments were performed with similar results. cal component of the SA signaling pathway) were induced after inoculation (Fig. 6A). When compared with those in WT plants, however, the expression levels of $P R-1, P R-5$, and NPRl genes were increased in the ATAF1-SRDX plants but reduced in the ATAF1-OE plants after inoculation (Fig. 6A). Expression of $P R-3$ was unchanged in WT, ATAF1-SRDX, and ATAF1-OE plants after infection. When compared with those in WT plants, however, the expression levels of PDF1.2 were reduced in the ATAF1-SRDX plants but increased in the ATAF1-OE plants after infection (Fig. 6A).

We further compared the expression levels of defenserelated genes in response to Botrytis spp. inoculation. After inoculation with $B$. cinerea, expression of the $P R-1, P R-3, P R$ 5, and $P D F 1.2$ genes as well as $B I K 1$ was induced in WT plants (Fig. 6B). However, the expression levels of $P R-1, P R$ 5 , and PDF1.2 genes were increased in the ATAF1-SRDX plants but reduced in the ATAF1-OE plants compared with those in WT plants after infection (Fig. 6B). The expression level of $P R$-3 was comparable among WT, ATAF1-SRDX, and ATAF1-OE plants after infection. After Botrytis spp. infection, the expression levels of $B I K 1$ in the ATAF1-SRDX plants were similar to those in WT plants, but the level in the ATAF1-OE plants was increased (Fig. 6B).

Collectively, these data indicate that enhanced resistance of the ATAF1-SRDX plants against $P$. syringae pv. tomato DC3000 and B. cinerea may be ascribed to the increased expression of defense genes after pathogen infection and that increased susceptibility of the ATAF1-OE plants may be a result of loss of activation of defense gene expression upon pathogen infection.

\section{Attenuation of SA-induced defense response in ATAF1-OE plants.}

Because expression of ATAF1 was downregulated by SA and expression of NPR1 in ATAF1-OE plants was upregulated after infection by $P$. syringae pv. tomato DC3000, we hypothesized that ATAF1 might have a function in SA-induced disease resistance response. To test this hypothesis, we compared the expression of $P R-1$ and $P R-5$ genes in WT and ATAF1-OE plants after SA treatment. In WT plants, SA significantly induced expression of $P R-1$ and $P R-5$ genes at 24 h after treatment (Fig. 7A). Although SA also induced expression of $P R-1$ and $P R-5$ in ATAF1-OE no. 1 and 7 plants, their expression was lower than in WT plants. Furthermore, SA-induced disease resistance in the ATAF1-OE plants was also assessed by comparing disease phenotype and bacterial population in waterand SA-treated WT and ATAF1-OE plants after inoculation with $P$. syringae pv. tomato DC3000. For this purpose, waterand SA-treated WT and ATAF1-OE plants were inoculated by infiltration with $P$. syringae pv. tomato DC3000 at $24 \mathrm{~h}$ after SA treatment. The SA-treated WT plants showed less disease than the water-treated plants at 4 days after inoculation. Disease phenotypes in the SA-treated ATAF1-OE plants were comparable with those in water-treated plants but were much more severe than those in WT plants (Fig. 7B). At 3 days after inoculation, the bacterial populations were measured as $1.21 \times$ $10^{7} \mathrm{CFU} / \mathrm{cm}^{2}$ and approximately 1.12 to $1.16 \times 10^{8} \mathrm{CFU} / \mathrm{cm}^{2}$ in water-treated WT and ATAF1-OE plants, and as $1.15 \times 10^{6}$ $\mathrm{CFU} / \mathrm{cm}^{2}$ and approximately 1.58 to $1.76 \times 10^{7} \mathrm{CFU} / \mathrm{cm}^{2}$ in SA-treated WT and ATAF1-OE plants, respectively (Fig. 7C). The ratio of bacterial populations in water-treated/SA-treated WT plants was 10.52 , whereas this ration was approximately 6.59 to 7.08 for the ATAF1-OE plants, indicating a relatively higher level of bacterial population in the ATAF1-OE plants than in the WT plants. These results suggest that the SAinduced disease resistance was attenuated in ATAF1-OE plants upon SA treatment. 
Accumulation of ROS in ATAF1-OE and

ATAF1-SRDX plants after Botrytis spp. infection.

ROS have been implicated in susceptible responses against necrotrophic fungus (Mengiste et al. 2003; Veronese et al. 2006). We determined and compared the production of ROS in WT, ATAF1-OE, ataf1-2, and ATAF1-SRDX plants after $B$. cinerea inoculation. In situ $\mathrm{H}_{2} \mathrm{O}_{2}$ production was detected using
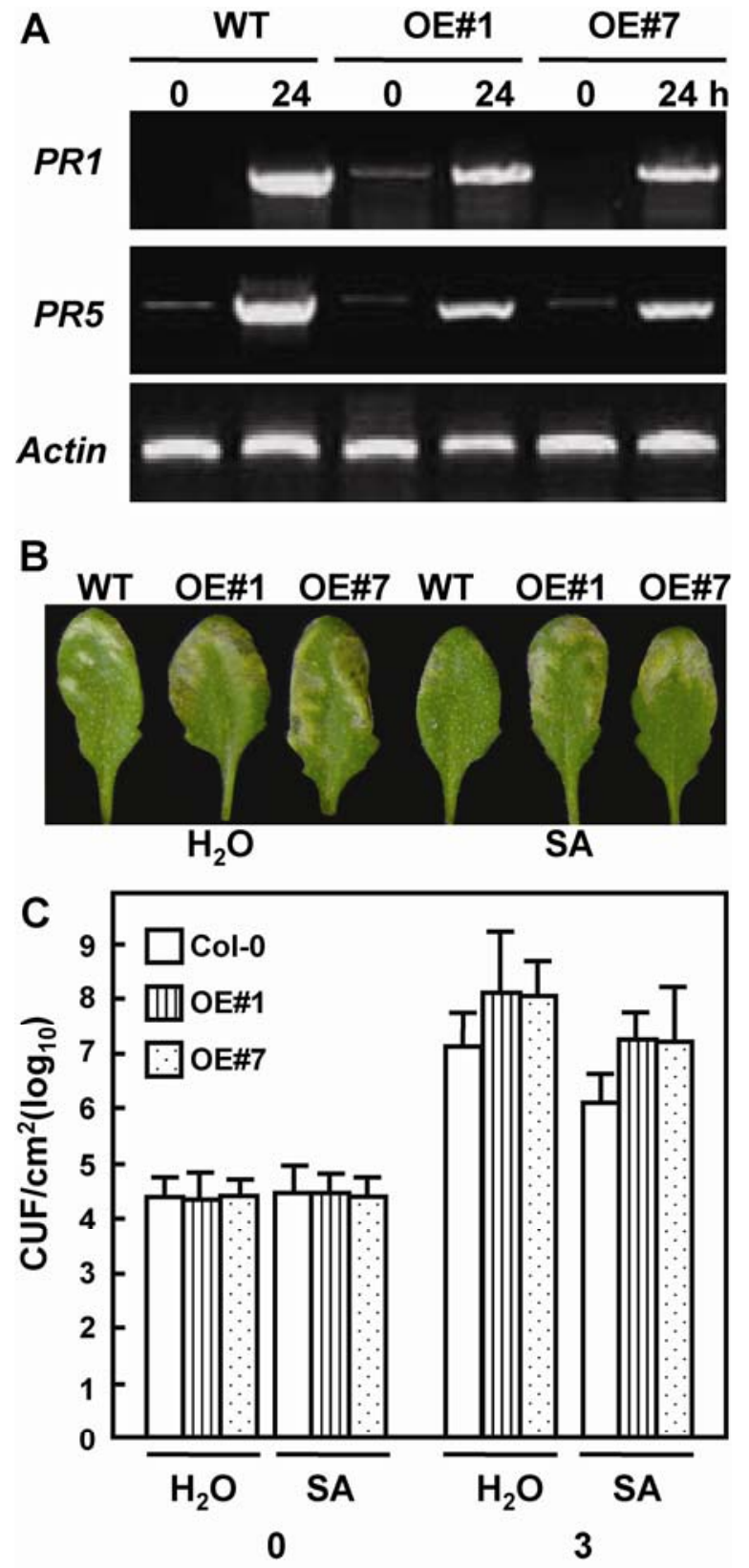

Days after infection

Fig. 7. Attenuation of salicylic acid (SA)-induced defense response in ATAF1-OE plants. A, Expression of pathogenesis-related $(P R)$ genes in ATAF1-OE plants after SA treatment. Four-week-old wild-type (WT) and ATAF1-OE plants were treated by foliar spray of $1 \mathrm{mM} \mathrm{SA}$ and leaf samples were collected for reverse-transcriptase polymerase chain reaction analysis of $P R$ gene expression. $\mathbf{B}$ and $\mathbf{C}$, Partial suppression of SAinduced disease resistance against $P$. syringae pv. tomato DC3000 in ATAF1-OE plants. Four-week-old plants were treated by foliar spraying with $1 \mathrm{mM}$ SA or water as control and infiltration-inoculated with $P$. syringae pv. tomato DC3000 (optical density at $600 \mathrm{~nm}=0.002$ ) $24 \mathrm{~h}$ later. B, Photos were taken 4 days after inoculation and $\mathbf{C}$, bacterial titers were measured. Data presented are the means \pm standard deviation from three independent experiments. diaminobenzidine, which forms a visible reddish-brown polymer in tissue (Thordal-Christensen et al. 1997). The accumulation of superoxide anions $\left(\mathrm{O}_{2}^{-}\right)$was tested by staining with nitroblue tetrazolium (Doke 1983). In mock-inoculated plants, no significant accumulation of $\mathrm{H}_{2} \mathrm{O}_{2}$ and $\mathrm{O}_{2}{ }^{-}$was observed (Fig. 8A and B), indicating that the plants used for the experiments were not stressed. At $48 \mathrm{~h}$ after inoculation with $\mathrm{B}$. cinerea, significant accumulation of $\mathrm{H}_{2} \mathrm{O}_{2}$ and $\mathrm{O}_{2}^{-}$was detected in leaves of WT plants (Fig. 8A and B). However, much more $\mathrm{H}_{2} \mathrm{O}_{2}$ and $\mathrm{O}_{2}^{-}$were generated in leaves of the ATAF1-OE plants than in those of WT plants. By contrast, less $\mathrm{H}_{2} \mathrm{O}_{2}$ and $\mathrm{O}_{2}^{-}$was detected in leaves of ATAF1-SRDX and ataf1-2 plants,
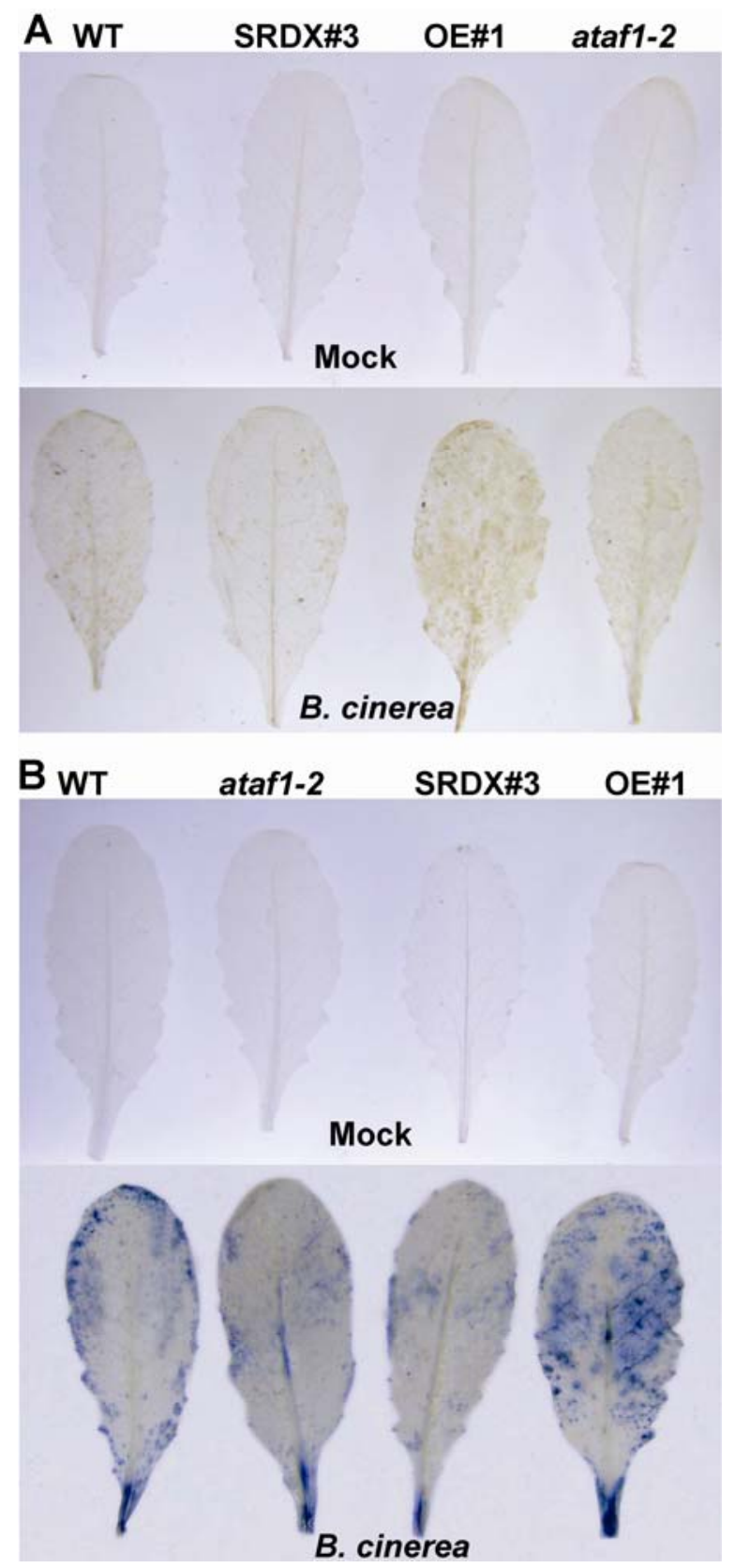

Fig. 8. Comparison of reactive oxygen species accumulation in wild-type (WT), ataf1-2, ATAF1-SRDX, and ATAF1-OE plants after Botrytis cinerea inoculation. Four-week-old plants were inoculated by spraying with spores of B. cinerea or mock inoculated and leaf samples were taken $48 \mathrm{~h}$ after inoculation. Accumulation of $\mathbf{A}, \mathrm{H}_{2} \mathrm{O}_{2}$ and $\mathbf{B}$, superoxide anion in leaves was detected by 3,3-diaminobenzidine and nitroblue tetrazolium staining, respectively. The experiments were repeated twice with similar results. 
especially in the ATAF1-SRDX plants, in which only limited staining of $\mathrm{H}_{2} \mathrm{O}_{2}$ and $\mathrm{O}_{2}^{-}$was observed (Fig. 8A and B).

\section{DISCUSSION}

It has been shown recently that Arabidopsis ATAF1 acts as a negative regulator of drought tolerance and mediates efficient penetration resistance against nonhost pathogens by attenuation of abscissic acid (ABA) signaling (Lu et al. 2007; Jensen et al. 2007, 2008). In the present study, through comparative analysis of disease phenotypes in transgenic overexpression lines and transgenic chimeric repressor lines, we provide direct genetic evidence supporting ATAF1 functions as a negative regulator of plant disease resistance against both different types of pathogens.

Expression of ATAF1 and its rice, barley, and potato homologues (OsNAC6, HvNAC6, and StNAC, respectively) is induced in response to pathogen infection as well as hormones (ABA and methyl JA) and abiotic stress (dehydration and wounding) (Collinge and Boller 2001; Schenk et al. 2003; Ohnishi et al. 2005; de Torres-Zabala et al. 2007; Jensen et al. 2007; Lu et al. 2007; Nakashima et al. 2007). Expression of $A T A F 1$ was only induced at $12 \mathrm{~h}$ during a 48 -h period after infection with the nonhost pathogen Blumeria graminis f. sp. hordei and during late stage (after $48 \mathrm{~h}$ ) of infection by $A$. brassicicola (Jensen et al. 2007; Schenk et al. 2003). In our study, however, we found that expression of ATAF1 was downregulated in response to infection by Botrytis cinerea and $P$. syringae pv. tomato DC3000 as well as to treatments with SA and JA. This is similar to a previous observation for the transcription factor gene AtWRKY48, whose expression was rapidly suppressed by infection with $P$. syringae pv. tomato DC3000 (Xing et al. 2008). Interestingly, pathogen- or SA-induced downregulation of ATAF1 expression showed different patterns in some mutant plants; for example, the expression level of $A T A F 1$ in bikl and NahG plants was not significantly downregulated after infection with $B$. cinerea or $P$. syringae pv. tomato DC3000 and SA treatment. Theoretically, a large set of genes encoding both positive and negative defense regulators is often coordinately activated in plants upon pathogen infection, and expression of those genes for negative regulators must be suppressed to activate efficient defense responses on time. Suppression of ATAF1 expression may be one of the defense responses activated in plants after pathogen infection.

Functional redundancy in the NAC family is a very common phenomenon; for examples, CUC1/CUC2 (Aida et al. 1997), NST1/NST2 (Mitsuda et al. 2005), ANAC019/ANAC055 (Bu et al. 2008), and ATAF2/At5g63790 (Delessert et al. 2005) are functionally redundant pairs of NAC genes in Arabidopsis. TDNA insertion mutants for individual members of the abovementioned NAC pairs showed no visible phenotypic changes compared with WT plants, and altered phenotypes were observed only in double mutants of cucl/cuc2, nst $1 /$ nst 2 , and anac019/anac055 (Aida et al. 1997; Mitsuda et al. 2005; Bu et al. 2008). In our experiments, we were unable to observe significant changes in disease phenotypes in atafl-2 plants after inoculation with $B$. cinerea and $P$. syringae pv. tomato DC3000. This is similar to the observation for ATAF2, whose T-DNA-tagged knockout mutants did not show any change in disease resistance against $F$. oxysporum (Delessert et al. 2005). The chimeric repressor gene-silencing strategy can overcome functional redundancy of highly related genes and has been widely used in elucidating biological functions of a number of genes encoding transcriptional factors, including NAC proteins (Fujita et al. 2004; Mitsuda et al. 2005, 2007, 2008). In our study, ATAF1-SRDX plants showed increased disease resistance against infection with different pathogens than the atafl-
2 plants, indicating that functional redundancy is also the case for the ATAF1 gene. Phylogenetically, the ATAF1 protein has a high level of identity to At $1 \mathrm{~g} 77450$, whose function is not yet determined; thus, it is possible that disruption of ATAF1 in atafl-2 plants may be compensated by At1g77450. With respect to this, it would be interesting to characterize the biological function of At1g77450 in biotic and abiotic stresses using overexpression and chimeric repressor transgenic plants as well as double mutants between the atafl and at $1 g 77450$ lines.

ATAF1 belongs to a small subfamily of NAC proteins called the ATAF subfamily. An ATAF1 knockout mutant, atafl-1, shows decreased penetration resistance to nonhost pathogen Blumeria graminis f. sp. hordei and ATAF1 acts as a new stimuli-dependent attenuator of ABA signaling for the mediation of efficient penetration resistance upon $B$. graminis f. sp. hordei infection (Jensen et al. 2007, 2008). In contrast to these observations, we found that disruption of ATAF1 function by chimeric dominant repression at protein activity levels conferred enhanced disease resistance against different types of adapted pathogens, whereas overexpression of ATAF1 resulted in increased susceptibility. Our gain-of-function and loss-of-function evidence supports the idea that ATAF1 acts as a negative regulator of defense response. It has also been found that ATAF2, a member of the ATAF subfamily very closely related to ATAF1, and ANAC019/ANAC055 are negative regulators of defense response against $F$. oxysporum and Botrytis cinerea, respectively (Delessert et al. 2005; Bu et al. 2008). These observations imply that plants have developed distinct mechanisms to regulate basal resistance toward nonhost pathogens and defense responses against different types of adapted pathogens. This is supported by previous observations for the Arabidopsis pen 1 and pen 3 mutants, which are more susceptible to entry of the nonhost fungus Blumeria graminis f. sp. hordei but are more resistant to the Arabidopsis powdery mildew fungus Erysiphe cichoracearum (Stein et al. 2006; Zhang et al. 2007). Moreover, the ATAF1 homologues of the monocot plants (i.e., rice OsNAC6 and barley HvNAC6) have been shown to play positive roles in regulation of defense responses. Silencing of HvNAC6 compromises penetration resistance in barley epidermal cells toward virulent $B$. graminis f. sp. hor$d e i$, while transient overexpression of $H v N A C 6$ increases the occurrence of penetration-resistant cells toward B. graminis $\mathrm{f}$. sp. hordei attack (Jensen et al. 2007). Similarly, overexpression of OsNAC6 in rice resulted in slightly increased resistance to blast disease (Nakashima et al. 2007). Therefore, function of ATAF1 in disease resistance between dicot and monocot plants might also be different.

Defense responses against $P$. syringae pv. tomato DC3000 and necrotrophic pathogens are thought to be mediated by SAand JA/ET-dependent signaling pathways, respectively (Glazebrook 2005). Both negative and positive cross-talk between $\mathrm{JA} / \mathrm{ET}$ and SA signaling exist in plants in response to pathogen infections (Glazebrook 2005; Mur et al. 2006; Schenk et al. 2000). ATAF1 may have functions in both the SA- and JA/ETdependent signaling pathways. This is supported by several lines of evidence obtained from our studies. First, expression of ATAF1 was downregulated after infection by both Botrytis cinerea and $P$. syringae pv. tomato DC3000 and by treatments of SA and JA. Second, disruption of ATAF1 function resulted in enhanced resistance against $P$. syringae pv. tomato DC 3000 and necrotrophic pathogens, including $B$. cinerea and $A$. brassicicola, whereas overexpression of $A T A F 1$ led to increased susceptibility to these pathogens. Third, both SA- and JAresponsive defense genes were activated in ATAF1-SRDX plants upon infection with $P$. syringae pv. tomato DC3000 and $B$. cinerea. The function of ATAF1 in SA-mediated defense response is further confirmed by the observation that the SA- 
and $P$. syringae pv. tomato DC3000-induced expression of SAresponsive $P R$ genes and SA-induced disease resistance against $P$. syringae pv. tomato DC3000 was attenuated in the ATAF1-OE plants. The fact that expression of ATAF1 in NahG plants was not downregulated as much as in WT and nprl plants after $P$. syringae pv. tomato DC3000 infection or SA treatment and expression of NPRI in the ATAF1-SRDX plants after infection of $P$. syringae pv. tomato DC 3000 was further induced may suggest that ATAF1 has a function upstream of NPR1 but downstream of SA in the SA signaling pathway. However, genetic evidence is required to validate this possibility.

It was shown that BIK1 is required for activation of defense response against necrotrophic fungi, including $B$. cinerea and A. brassicicola (Veronese et al. 2005). Altered disease resistance, resulting from SRDX-mediated disruption of ATAF1 function and overexpression of ATAF1 in WT plants, in which BIK1 has normal function as a positive regulator of Botrytis spp. resistance, provide no direct evidence regarding the genetic relationship between BIK1 and ATAF1 in modulating defense response against $B$. cinerea. The observations that expression of ATAF1 was not suppressed in bikl plants after Botrytis spp. infection and that the ATAF1-OE plants showed increased susceptibility to Botrytis spp. suggest that ATAF1 may act downstream of BIK1. However, this is contradictory to some extent to the observation that expression of BIK1 was not induced by $B$. cinerea in ATAF1-SRDX plants. Therefore, it seems that a feedback interaction between function of ATAF1 and BIK1 is involved in regulation of defense response against $B$. cinerea. This will be clarified by further analysis of disease resistance phenotypes in transgenic plants constitutively expressing chimeric repressor construct ATAF1-SRDX in bikl background.

Neither growth or development defects nor constitutively activated defense response (expression of $P R$ genes and accumulation of ROS) was observed in the ATAF1-SRDX plants, which showed enhanced disease resistance after pathogen infection. However, defense responses, including expression of $P R$ genes, were activated in ATAF1-SRDX plants when challenged with $B$. cinerea and $P$. syringae pv. tomato DC3000. Production of ROS, which is related to susceptibility to necrotrophic pathogens, including B. cinerea, in some Arabidopsis mutants (Mengiste et al. 2003; Veronese et al. 2006), was suppressed in ATAF1-SRDX plants after inoculation with $B$. cinerea. It is likely that disruption of ATAF1 potentiates the rapid and strong activation of defense in response to attempted infection. This is similar to the observation for AtWRKY18, a pathogen- and SA-induced WRKY transcription factor, which potentiates developmentally regulated defense responses in transgenic plants when expressed at moderate levels (Chen and Chen 2000). On the other hand, expression of $P R$ and $P D F 1.2$ genes was differentially upregulated in ATAF1-SRDX and ATAF1-OE plants upon infection with different pathogens. When inoculated with $P$. syringae pv. tomato DC3000, expression of some of the SA-responsive $P R$ genes was upregulated, whereas expression of $P D F 1.2$ was suppressed in ATAF1SRDX plants. In contrast, infection with $B$. cinerea induced significant expression of both SA-responsive and JA-responsive defense genes in ATAF1-SRDX plants, which is in agreement with previous observations that resistance to $B$. cinerea involves an SA signaling pathway and activation of $P R$ gene expression in Arabidopsis (Govrin and Levine 2002; Ferrari et al. 2003; Zheng et al. 2006). Interestingly, a pathogen-specific effect on $P D F 1.2$ expression was observed, showing a positive correlation with $A T A F 1$ expression levels after $P$. syringae pv. tomato DC3000 infection and a negative correlation after $\mathrm{Bo}$ trytis spp. infection. This might be ascribed to negative cross- talk between SA- and ET/JA-signaling pathways that mediate the defense response against $P$. syringae pv. tomato DC3000 and necrotrophic pathogens, respectively (Glazebrook 2005). Thus, disruption of ATAF1 function in ATAF1-SRDX plants seems to potentiate a fine-tuned mechanism to efficiently regulate distinct defense responses upon infection with different pathogens.

Taken together, evidence from our study and others ( $\mathrm{Lu}$ et al. 2007; Jensen et al. 2007, 2008) indicates that ATAF1 represents a node of convergence regulating plant defense and drought tolerance to multiple abiotic and biotic stress factors. Previous studies have shown that ATAF1 and its rice and barley homologues OsNAC6 and HvNAC6 are biochemically transcriptional activators rather than transcriptional repressors (Lu et al. 2007; Jensen et al. 2007; Nakashima et al. 2007). Therefore, it is unlikely that ATAF1 directly suppresses expression of downstream target genes. Instead, ATAF1 may first activate expression of some unknown negative regulators, which in turn repress expression of defense genes. Further identification of downstream target genes and their functions will provide new insights into how ATAF1 negatively regulates defense responses to different types of pathogens.

\section{MATERIALS AND METHODS}

\section{Plant growth and treatment.}

Arabidopsis thaliana WT ecotype Col-0, mutant, and transgenic plants were grown on soil in a growth room at $23^{\circ} \mathrm{C}$ under long-day conditions (cycle of $16 \mathrm{~h}$ of light and $8 \mathrm{~h}$ of darkness) with a relative humidity $(\mathrm{RH})$ of $70 \%$. For chemical treatments, SA ( $1 \mathrm{mmol} / \mathrm{liter}), \mathrm{BTH}(300 \mu \mathrm{mol} / \mathrm{liter}), \mathrm{JA}$ (100 $\mu \mathrm{mol} /$ liter $)$, and ACC (100 $\mu \mathrm{mol} /$ liter $)$ were prepared in water and applied as a spray to 4-week-old plants. The treated plants were kept at $100 \%$ RH and then harvested at the indicated times. Samples were collected at different time point and the 0 -h samples were collected immediately after inoculation or treatment.

\section{Plant inoculation and measurement of pathogen growth.}

$P$. syringae pv. tomato DC3000 was grown overnight in King's B $(\mathrm{KB})$ liquid medium containing rifampicin at 25 $\mu \mathrm{g} / \mathrm{ml}$, and the suspensions were diluted and regrown to an optical density at $600 \mathrm{~nm}\left(\mathrm{OD}_{600}\right)$ of approximately 0.7 to 1.0 . Bacteria were collected and resuspended in $10 \mathrm{mM} \mathrm{MgCl}_{2}$ to $\mathrm{OD}_{600}=0.002$ for plant inoculation. Four-week-old plants were infiltrated at two sites of two leaves with $20-\mu$ l aliquots of $P$. syringae pv. tomato $\mathrm{DC} 3000$ suspension or with $\mathrm{MgCl}_{2}$ solution as mock inoculation using a $1-\mathrm{ml}$ syringe without needle. After inoculation, plants were covered with a transparent plastic film and disease symptoms were observed daily. Six independent samples were used for the $P$. syringae growth curve measurement. Leaf punches (6 $\mathrm{mm}$ in diameter) were surface sterilized in $70 \%$ ethanol for $10 \mathrm{~s}$, homogenized in $200 \mu \mathrm{l}$ of $10 \mathrm{mM} \mathrm{MgCl} 2$, diluted in $10 \mathrm{mM} \mathrm{Mg} \mathrm{Cl}$, and plated on $\mathrm{KB}$ agar plates containing rifampicin at $100 \mu \mathrm{g} / \mathrm{ml}$.

$B$. cinerea was grown on $2 \times \mathrm{V} 8$ agar $(36 \%$ V8 juice, $0.2 \%$ $\mathrm{CaCO}_{3}$, and $2 \%$ agar) at $20^{\circ} \mathrm{C}$. Conidia were collected from 10 -day-old cultures by placing agar slices containing fungal material in $1 \%$ maltose buffer and vortexing to release the spores. The spore suspension was passed through two layers of cheesecloth and spore density was adjusted to $2 \times 10^{5}$ spores $/ \mathrm{ml}$. Inoculation was performed by foliar spraying with spore suspension in a fine mist onto leaves of 4-week-old plants. The inoculated plants were covered with a transparent plastic film and kept at $22^{\circ} \mathrm{C}$ in a growth chamber under a cycle of $14 \mathrm{~h}$ of light and $10 \mathrm{~h}$ of darkness. Chlorophyll contents were measured as described previously (Mengiste et al. 
2003; Veronese et al. 2006) and expressed as percentages of the chlorophyll content in the corresponding mock-inoculated plants. Plants that were completely rotten were recorded as decayed plants. Fungal growth in leaf tissues was evaluated based on expression level of a Botrytis actin A (BcActin A) gene analyzed by RT-PCR using a pair of primers: BcActinA1F (5'-ACT CAT ATG TTG GAG ATG AAG CGC AA-3') and BcActinA-1R (5'-AAT GTT ACC ATA CAA ATC CTT ACG GAC A-3'). Expression of an Arabidopsis actin gene (AtActin) as an internal control was also analyzed by RT-PCR with primers of AtActin-1F (5'-GGC GAT GAA GCT CAA TCC AAA CG-3') and AtActin-1R (5'-GGT CAC GAC CAG CAA GAT CAA GAC G-3').

A. brassicicola was grown on potato dextrose agar for 10 days at room temperature and spores were collected and resuspended in $0.1 \%$ Tween 20 . Inoculation with $A$. brassicicola was performed by applying a 5 - $\mu$ ld drop of spore suspension $\left(5 \times 10^{5}\right.$ spores $/ \mathrm{ml}$ ) on each detached leaf of 4-week-old plants. Inoculated leaves were kept at $100 \% \mathrm{RH}$ in sealed dishes. The diameter of each lesion was measured after 6 days. To count the number of spores, 10 leaves were collected and shaken vigorously in $5 \mathrm{ml}$ of $0.1 \%$ Tween 20 in a test tube. Leaves were removed, and the spore-containing suspension was centrifuged at $5,000 \times g$ for $15 \mathrm{~min}$. The spores were resuspended in $200 \mu \mathrm{l}$ of $0.1 \%$ Tween 20 , serially diluted, and counted with a microscope.

\section{Genotyping of the ataf1 mutant.}

A SALK T-DNA insertion line, SALK_057618, was obtained from the Arabidopsis Biological Resource Center at Ohio State University. Gene-specific primers were used for screening of homozygous were SALK_057618-LP (5'-TCC CAG GGA CAG AAA ATA TCC-3') and SALK_057618-RP (5'-AAA TAT TAA ATT GAT TGC GGC AC-3'). A T-DNA primer LBa1 (5'-TGG TTC ACG TAG TGG GCC ATC G-3') was also included, as suggested on the T-DNA Express Web site. A three-primer PCR strategy was used to identify WT, heterozygous, and homozygous individuals in a single step using two gene-specific primers and LBa1. Plants homozygous for the ATAF1 mutation were used for further analysis.

\section{Generation and characterization of the transgenic lines.}

The cDNA of the ATAF1 gene was amplified using RT-PCR with a pair of gene-specific primers, ATAF1-1F (5'-ATG TCA GAA TTA TTA CAG TTG CCT C-3') and ATAF1-1R (5'-CTA GTA AGG CTT CTG CAT GAT C-3'). To construct the overexpression plasmid, the coding region of ATAF1 was amplified using a pair of primers, ATAF1-2F (5'-AGT GGA TCC ATG TCA GAA TTA TTA CAG TTG C-3') and ATAF1-2R (5'-GCG GGT ACC CTA GTA AGG CTT CTG CAT GTA C-3'), which contain a BamHI site and a KpnI site (underlined). To construct the ATAF1 chimeric repressor plasmid, the coding region without the stop codon was amplified using a pair of primers, ATAF1-2F and ATAF1-3R (5'-GCG GGT ACC TTA GGC AAA TCC AAG GCG GAG CTC CAG ATC TAG GTC GAG GGG CCC GTA AGG CTT CTG CAT GTA CAT G-3'). The reverse primer contains an ApaI site and a synthetic SRDX (LDLDLELRLGFA) coding sequence. The amplified fragments were cloned into the BamHI/KpnI or BamHI/ApaI sites of binary vector pCAMBIA 99-1 under control of the CaMV 35S promoter, respectively.

Arabidopsis transformation was performed using the floral dip method (Clough and Bent 1998). Seed from transformed plants (T0) were harvested and sown on half-strength Murashige-Skoog medium containing hygromycin (Hgr) at 50 $\mu \mathrm{g} / \mathrm{ml}$. Transformants of the T1 generation were selected and self pollinated. The progenies of the $\mathrm{T} 1$ transformants were observed on selective medium and 3:1 (Hgr-resistant/Hgr-sen- sitive) segregating lines were selected and transformed to soil for self pollination. Progeny (T2) of the individual T1 plants were observed on selective medium and those that showed 100\% resistance to Hgr were selected as homozygous lines.

\section{RT-PCR analysis of gene expression.}

Total RNA from leaves was extracted using the TRIZOL reagent according to the manufacturer's procedure (Invitrogen, Shanghai). First-strand cDNA was synthesized from $500 \mathrm{ng}$ of total RNA using superscript III reverse transcriptase (Invitrogen). Primers ATAF1-1F and $-1 \mathrm{R}$ that amplify the full open reading frame fragment were used for detection of ATAFl expression. Other primers used in this study were AtPR1-F, 5'TCG TCT TTG TAG CTC TTG TAG GTG-3'; AtPR1-R, 5'TAG ATT CTC GTA ATC TCA GCT CT-3'; AtPR5-F, 5'-ATG GCA AAT ATC TCC AGT ATT CAC A-3'; AtPR5-R, 5'-ATG TCG GGG CAA GCC GCG TTG AGG-3'; AtPDF1.2-F, 5'GCTA AGT TTG CTT CCA TCA TCA CCC TT-3'; and AtPDF1.2-R, 5'-AAC ATG GGA CGT AAC AGA TAC ACT TGT G-3'. Expression of a housekeeping gene (i.e., actin) was used as a control with a pair of primers, AtActin-1F (5'-GGC GAT GAA GCT CAA TCC AAA CG-3') and AtActin-1R (5'GGT CAC GAC CAG CAA GAT CAA GAC G-3'). PCR was performed for 28 to 32 cycles based on abundance of transcripts of the genes analyzed.

\section{Detection of ROS.}

Detection of $\mathrm{H}_{2} \mathrm{O}_{2}$ and superoxide anion in leaf tissues was performed by 3,3-diaminobenzidine (DAB) staining (ThordalChristensen et al. 1997) and nitroblue tetrazolium (NBT) staining (Doke et al. 1983), respectively. Leaf samples were collected from inoculated plants $48 \mathrm{~h}$ after inoculation. For staining of $\mathrm{H}_{2} \mathrm{O}_{2}$, individual leaf petioles were dipped into DAB (Sigma) solution ( $1 \mathrm{mg} / \mathrm{ml}, \mathrm{pH} \mathrm{3.8)}$ and incubated for $8 \mathrm{~h}$ in the dark at room temperature. Thereafter, leaves were removed, placed into acetic acid/glycerol/ethanol (1:1:1, vol/vol/vol), and boiled for $5 \mathrm{~min}$ in a water bath. Subsequently, the solution was exchanged and leaves were maintained in $60 \%$ glycerol. For staining of superoxide anion, leaves were vacuum infiltrated in $2 \mathrm{ml}$ of $10 \mathrm{mM}$ potassium phosphate buffer, $\mathrm{pH}$ 7.5, containing $10 \mathrm{mM} \mathrm{NaN}_{3}$ and $0.1 \% \mathrm{NBT}$ (Sigma) for 30 min at room temperature. Leaves were boiled in $96 \%$ ethanol for $10 \mathrm{~min}$ before visualizing blue precipitates.

\section{ACKNOWLEDGMENTS}

We thank the Arabidopsis Biological Resource Center at Ohio State University for the T-DNA insertion mutant. This work was supported by National Science Foundation of China (grant no. 30771399), National High-tech Project of China (2007AA10Z140), and National Basic Research Program of China (2006CB 101905 and 2009CB119005).

\section{LITERATURE CITED}

Aida, M., Ishida, T., Fukaki, H., Fujisawa, H., and Tasaka, M. 1997. Genes involved in organ separation in Arabidopsis: An analysis of the cupshaped cotyledon mutant. Plant Cell 9:841-857.

Benito, E. P., ten Have, A., van't Klooster, J. W., and van Kan, J. A. L. 1998. Fungal and plant gene expression during synchronized infection of tomato leaves by Botrytis cinerea. Eur. J. Plant Pathol. 104:207-220.

Bu, Q., Jiang, H., Li, C.B., Zhai, Q., Zhang, J., Wu, X., Sun, J., Xie, Q., and $\mathrm{Li}, \mathrm{C} .2008$. Role of the Arabidopsis thaliana NAC transcription factors ANAC019 and ANAC055 in regulating jasmonic acid-signaled defense responses. Cell Res. 18:756-767.

Chen, C., and Chen, Z. 2000. Isolation and characterization of two pathogen- and salicylic acid- induced genes encoding WRKY DNA-binding proteins from tobacco. Plant Mol. Biol. 42:387-396.

Clough, S. J., and Bent, A. F. 1998. Floral dip: A simplified method for Agrobacterium-mediated transformation of Arabidopsis thaliana. Plant J. 16:735-743. 
Collinge, M., and Boller, T. 2001. Differential induction of two potato genes, Stprx 2 and StNAC, in response to infection by Phytophthora infestans and to wounding. Plant Mol. Biol. 46:521-529.

Delessert, C., Kazan, K., Wilson, I. W., Van Der Straeten, D., Manners, J., Dennis, E. S., and Dolferus, R. 2005. The transcription factor ATAF2 represses the expression of pathogenesis-related genes in Arabidopsis. Plant J. 43:745-757

de Torres-Zabala, M., Truman, W., Bennett, M. H., Lafforgue, G., Mansfield, J. W., Egea, P. R., Bogre, L., and Grant, M. 2007. Pseudomonas syringae pv. tomato hijacks the Arabidopsis abscisic acid signalling pathway to cause disease. EMBO (Eur. Mol. Biol. Organ.) J. 26:1434-1443.

Doke, N. 1983. Involvement of superoxide anion generation in the hypersensitive response of potato tuber tissue to infection with an incompatible race of Phytophthora infestans and to the hyphal wall components. Physiol. Plant Pathol. 23:345-357.

Eulgem, T., and Somssich, I. E. 2007. Networks of WRKY transcription factors in defense signaling. Curr. Opin. Plant Biol. 10:366-371.

Fang, Y., You, J., Xie, K., Xie, W., and Xiong, L. 2008 Systematic sequence analysis and identification of tissue-specific or stress-responsive genes of NAC transcription factor family in rice. Mol. Genet. Genomics 280:547-563.

Ferrari, S., Plotnikova, J. M., De Lorenzo, G., and Ausubel, F. M. 2003. Arabidopsis local resistance to Botrytis cinerea involves salicylic acid and camalexin and requires EDS4 and PAD2, but not SID2, EDS5 or PAD4. Plant J. 35:193-205.

Fujita, M., Fujita, Y., Maruyama, K., Seki, M., Hiratsu, K., Ohme-Takagi, M., Tran, L. S., Yamaguchi-Shinozaki, K., and Shinozaki, K. 2004 A dehydration-induced NAC protein, RD26, is involved in a novel ABAdependent stress-signaling pathway. Plant J. 39:863-876.

Glazebrook, J. 2005. Contrasting mechanisms of defense against biotrophic and necrotrophic pathogens. Annu. Rev. Phytopathol. 43:205227

Govrin, E. M., and Levine, A. 2002. Infection of Arabidopsis with a necrotrophic pathogen, Botrytis cinerea, elicits various defense responses but does not induce systemic acquired resistance (SAR). Plant Mol. Biol. 48:267-276.

Guo, Y., and Gan, S. 2006. AtNAP, a NAC family transcription factor, has an important role in leaf senescence. Plant J. 46:601-612.

Gutterson, N., and Reuber, T. L. 2004. Regulation of disease resistance pathways by AP2/ERF transcription factors. Curr. Opin. Plant Biol. 7:465-471.

He, X. J., Mu, R. L., Cao, W. H., Zhang, Z. G., Zhang, J. S., and Chen, S. Y. 2005. AtNAC2, a transcription factor downstream of ethylene and auxin signaling pathways, is involved in salt stress response and lateral root development. Plant J. 44:903-916.

Hegedus, D., Yu, M., Baldwin, D., Gruber, M., Sharpe, A., Parkin, I., Whitwill, S., and Lydiate, D. 2003. Molecular characterization of Bras sica napus NAC domain transcriptional activators induced in response to biotic and abiotic stress. Plant Mol. Biol. 53:383-397.

Hiratsu, K., Matsui, K., Koyama, T., and Ohme-Takagi, M. 2003. Dominant repression of target genes by chimeric repressors that include the EAR motif, a repression domain, in Arabidopsis. Plant J. 34:733-739.

Hu, H., Dai, M., Yao, J., Xiao, B., Li, X., Zhang, Q., and Xiong, L. 2006. Overexpressing a NAM, ATAF, and CUC (NAC) transcription factor enhances drought resistance and salt tolerance in rice. Proc. Natl. Acad. Sci. U.S.A. 103:12987-12992.

Hu, H., You, J., Fang, Y., Zhu, X., Qi, Z., and Xiong, L. 2008. Characterization of transcription factor gene SNAC2 conferring cold and salt tolerance in rice. Plant Mol. Biol. 67:169-181.

Jensen, M. K., Rung, J. H., Gregersen, P. L., Gjetting, T., Fuglsang, A. T., Hansen, M., Joehnk, N., Lyngkjaer, M. F., and Collinge, D. B. 2007. The HvNAC6 transcription factor: A positive regulator of penetration resistance in barley and Arabidopsis. Plant Mol. Biol. 65:137-150.

Jensen, M. K., Hagedorn, P. H., de Torres-Zabala, M., Grant, M. R., Rung, J. H., Collinge, D. B., and Lyngkjaer, M. F. 2008. Transcriptional regulation by a NAC (NAM-ATAF1,2-CUC2) transcription factor attenuates ABA signalling for efficient basal defence towards Blumeria graminis f. sp. hordei in Arabidopsis. Plant J. 56:867-880.

Jeong, R. D., Chandra-Shekara, A. C., Kachroo, A., Klessig, D. F., and Kachroo, P. 2008. HRT-mediated hypersensitive response and resistance to Turnip crinkle virus in Arabidopsis does not require the function of TIP, the presumed guardee protein. Mol. Plant-Microbe Interact. 21:1316-1324.

Kim, S. G., Lee, A. K., Yoon, H. K., and Park, C. M. 2008. A membranebound NAC transcription factor NTL8 regulates gibberellic acid-mediated salt signaling in Arabidopsis seed germination. Plant J. 55:77-88.

Kim, Y. S., Kim, S. G., Park, J. E., Park, H. Y., Lim, M. H., Chua, N. H. and Park, C. M. 2006. A membrane-bound NAC transcription factor regulates cell division in Arabidopsis. Plant Cell 18:3132-3144.
Lu, P. L., Chen, N. Z., An, R., Su, Z., Qi, B. S., Ren, F., Chen, J., and Wang, X. C. 2007. A novel drought-inducible gene, ATAF1, encodes a NAC family protein that negatively regulates the expression of stressresponsive genes in Arabidopsis. Plant Mol. Biol. 63:289-305.

Mengiste, T., Chen, X., Salmeron, J., and Dietrich, R. 2003. The BOTRYTIS SUSCEPTIBLE1 gene encodes an R2R3MYB transcription factor protein that is required for biotic and abiotic stress responses in $\mathrm{Arabi}$ dopsis. Plant Cell 15:2551-2565.

Mitsuda, N., Seki, M., Shinozaki, K., and Ohme-Takagi, M. 2005. The NAC transcription factors NST1 and NST2 of Arabidopsis regulate secondary wall thickenings and are required for anther dehiscence. Plant Cell 17:2993-3006.

Mitsuda, N., Iwase, A., Yamamoto, H., Yoshida, M., Seki, M., Shinozaki, K., and Ohme-Takagi, M. 2007. NAC transcription factors, NST1 and NST3, are key regulators of the formation of secondary walls in woody tissues of Arabidopsis. Plant Cell 19:270-280.

Mitsuda, N., Umemura, Y., Ikeda, M., Shikata, M., Koyama, T., Matsui, K., Narumi, T., Aida, R., Sasaki, K., Hiyama, T., Higuchi, Y., Ono, M., Isuzugawa, K., Saitoh, K., Endo, R., Ikeda, K., Nakatsuka, T., Nishihara, M., Yamamura, S., Yamamura, T., Terakawa, T., Ohtsubo, N., and Ohme-Takagi, M. 2008. FioreDB: A database of phenotypic information induced by the chimeric repressor silencing technology (CRES-T) in Arabidopsis and floricultural plants. Plant Biotechnol. 25:37-43.

Mur, L. A., Kenton, P., Atzorn, R., Miersch, O., and Wasternack, C. 2006. The outcomes of concentration-specific interactions between salicylate and jasmonate signaling include synergy, antagonism, and oxidative stress leading to cell death. Plant Physiol. 140:249-262.

Nakashima, K., Tran, L. S., Van Nguyen, D., Fujita, M., Maruyama, K., Todaka, D., Ito, Y., Hayashi, N., Shinozaki, K., and YamaguchiShinozaki, K. 2007. Functional analysis of a NAC-type transcription factor OsNAC6 involved in abiotic and biotic stress-responsive gene expression in rice. Plant J. 51:617-630.

Ogo, Y., Kobayashi, T., Nakanishi, Itai, R., Nakanishi, H., Kakei, Y., Takahashi, M., Toki, S., Mori, S., and Nishizawa, N. K. 2008. A novel NAC transcription factor, IDEF2, that recognizes the iron deficiencyresponsive element 2 regulates the genes involved in iron homeostasis in plants. J. Biol. Chem. 283:13407-13417.

Oh, S. K., Lee, S., Yu, S. H., and Choi, D. 2005. Expression of a novel NAC domain-containing transcription factor (CaNAC1) is preferentially associated with incompatible interactions between chili pepper and pathogens. Planta 222:876-887.

Ohnishi, T., Ohnishi, T., Sugahara, S., Yamada, T., Kikuchi, K., Yoshiba Y., Hirano, H. Y., and Tsutsumi, N. 2005. OsNAC6, a member of the NAC gene family, is induced by various stresses in rice. Genes Genet. Syst. 80:135-139.

Olsen, A. N., Ernst, H. A., Leggio, L. L., and Skriver, K. 2005. NAC transcription factors: Structurally distinct, functionally diverse. Trends Plant Sci. 10:79-87.

Ooka, H., Satoh, K., Doi, K., Nagata, T., Otomo, Y., Murakami, K., Matsubara, K., Osato, N., Kawai, J., Carninci, P., Hayashizaki, Y., Suzuki, K., Kojima, K., Takahara, Y., Yamamoto, K., and Kikuchi, S. 2003. Comprehensive analysis of NAC family genes in Oryza sativa and Arabidopsis thaliana. DNA Res. 10:239-247.

Ren, T., Qu, F., and Morris, T. J. 2000. HRT gene function requires interaction between a NAC protein and viral capsid protein to confer resistance to Turnip crinkle virus. Plant Cell 12:1917-1926.

Sablowski, R. W., and Meyerowitz, E. M. 1998. A homolog of NO API$C A L M E R I S T E M$ is an immediate target of the floral homeotic genes APETALA3/PISTILLATA. Cell 92:93-103.

Schenk, P. M., Kazan, K., Wilson, I., Anderson, J. P., Richmond, T. Somerville, S. C., and Manners, J. M. 2000. Coordinated plant defense responses in Arabidopsis revealed by microarray analysis. Proc. Natl. Acad. Sci. U.S.A. 97:11655-11660.

Schenk, P. M., Kazan, K., Manners, J. M., Anderson, J. P., Simpson, R. S., Wilson, I. W., Somerville, S. C., and Maclean, D. J. 2003. Systemic gene expression in Arabidopsis during an incompatible interaction with Alternaria brassicicola. Plant Physiol. 132:999-1010.

Selth, L. A., Dogra, S. C., Rasheed, M. S., Healy, H., Randles, J. W., and Rezaian, M. A. 2005. A NAC domain protein interacts with tomato leaf curl virus replication accessory protein and enhances viral replication. Plant Cell 17:311-325

Souer, E., van Houwelingen, A., Kloos, D., Mol, J., and Koes, R. 1996. The no apical meristem gene of Petunia is required for pattern formation in embryos and flowers and is expressed at meristem and primordia boundaries. Cell 85:159-170.

Stein, M., Dittgen, J., Sanchez-Rodriguez, C., Hou, B. H., Molina, A., Schulze-Lefert, P., Lipka, V., and Somerville, S. 2006. Arabidopsis PEN3/PDR8, an ATP binding cassette transporter, contributes to nonhost resistance to inappropriate pathogens that enter by direct penetration. Plant Cell 18:731-746. 
Thordal-Christensen, H., Zhang, Z., Wei, Y., and Collinge, D. B. 1997. Subcellular localization of $\mathrm{H}_{2} \mathrm{O}_{2}$ in plants. $\mathrm{H}_{2} \mathrm{O}_{2}$ accumulation in papillae and hypersensitive response during the barley-powdery mildew interaction. Plant J. 11:1187-1194.

Tran, L. S., Nakashima, K., Sakuma, Y., Simpson, S. D., Fujita, Y., Maruyama, K., Fujita, M., Seki, M., Shinozaki, K., and YamaguchiShinozaki, K. 2004. Isolation and functional analysis of Arabidopsis stress-inducible NAC transcription factors that bind to a drought-responsive cis-element in the early responsive to dehydration stress 1 promoter. Plant Cell 16:2481-2498.

Tran, L. S., Nakashima, K., Sakuma, Y., Osakabe, Y., Qin, F., Simpson, S. D., Maruyama, K., Fujita, Y., Shinozaki, K., and Yamaguchi-Shinozaki, K. 2007. Co-expression of the stress-inducible zinc finger homeodomain ZFHD1 and NAC transcription factors enhances expression of the ERD1 gene in Arabidopsis. Plant J. 49:46-63.

Uauy, C., Distelfeld, A., Fahima, T., Blechl, A., and Dubcovsky, J. 2006. A NAC gene regulating senescence improves grain protein, zinc, and iron content in wheat. Science 314:1298-1301.

Veronese, P., Nakagami, H., Bluhm, B., Abuqamar, S., Chen, X., Salmeron, J., Dietrich, R. A., Hirt, H., and Mengiste, T. 2006. The membraneanchored BOTRYTIS-INDUCED KINASE1 plays distinct roles in Arabidopsis resistance to necrotrophic and biotrophic pathogens. Plant Cell 18:257-273.

Xie, Q., Frugis, G., Colgan, D., and Chua, N. H. 2000. Arabidopsis NAC1 transduces auxin signal downstream of TIR1 to promote lateral root development. Genes Dev. 14:3024-3036.

Xing, D.-H., Lai, Z.-B., Zheng, Z.-Y., Vinoda, K. M., Fan, B.-F., and Chen, Z.-X. 2008. Stress- and pathogen-induced Arabidopsis WRKY48 is a transcriptional activator that represses plant basal defense. Mol. Plant 1:459-470.
Yoo, S. Y., Kim, Y., Kim, S. Y., Lee, J. S., and Ahn, J. H. 2007. Control of flowering time and cold response by a NAC-domain protein in Arabidopsis. PLoS ONE 2:e642.

Yoon, H. K., Kim, S. G., Kim, S. Y., and Park, C. M. 2008. Regulation of leaf senescence by NTL9-mediated osmotic stress signaling in Arabidopsis. Mol. Cells 25:438-445.

Yoshii, M., Shimizu, T., Yamazaki, M., Higashi, T., Miyao, A., Hirochika, H., and Omura, T. 2008. Disruption of a novel gene for a NAC-domain protein in rice confers resistance to Rice dwarf virus. Plant J. 57:615625.

Zhang, Z., Feechan, A., Pedersen, C., Newman, M. A., Qiu, J. L., Olesen, K. L., and Thordal-Christensen, H. 2007. A SNARE-protein has opposing functions in penetration resistance and defence signalling pathways. Plant J. 49:302-312.

Zheng, Z., Qamar, S. A., Chen, Z., and Mengiste, T. 2006. Arabidopsis WRKY33 transcription factor is required for resistance to necrotrophic fungal pathogens. Plant J. 48:592-605.

Zheng, X., Chen, B., Lu, G., and Han, B. 2009. Overexpression of a NAC transcription factor enhances rice drought and salt tolerance. Biochem. Biophys. Res. Commun. 379:985-989.

Zhong, R., Demura, T., and Ye, Z. H. 2006. SND1, a NAC domain transcription factor, is a key regulator of secondary wall synthesis in fibers of Arabidopsis. Plant Cell 18:3158-3170.

\section{AUTHOR-RECOMMENDED INTERNET RESOURCES}

FioreDB database: www.cres-t.org/fiore/public_db/f_help.shtml

Salk Institute Genomic Analysis Laboratory T-DNA Express website, www.signal.salk.edu 